\title{
RESÍDUOS SÓLIDOS DE SAÚDE GERADOS POR USUÁRIOS DE INSULINA EM DOMICÍLIO: UMA ANÁLISE DA SEGREGAÇÃO, ACONDICIONAMENTO E DESTINAÇÃO FINAL
}

\author{
SOLID HEALTH WASTE GENERATED BY HOUSEHOLD INSULIN USERS: AN ANALYSIS OF \\ SEGREGATION, PACKAGING AND FINAL DESTINATION
}

Gissele Nardini Artigas de Oliveira ${ }^{a}$, Aline Belem Machado ${ }^{b}$, Kalinkaluei Aparecida Rigo ${ }^{b}$, Micaela da Silva Constante $^{b}$, Vanusca Dalosto Jahnoc ${ }^{c}$ Daniela Montanari Migliavacca Osorioc, Daiane Bolzan Berlese ${ }^{c}$.

$$
\text { Universidade Feevale - Feevale - Novo Hamburgo/RS }
$$

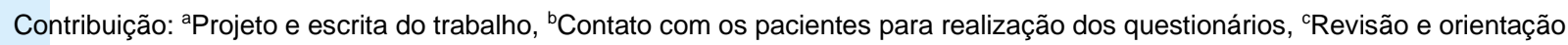

gica.nardini@gmail.com, linebmachado@hotmail.com, kalinkarigo@hotmail.com, micaelaconstante.19@gmail.com, vanusca@feevale.br, danielaosorio@feevale.br, daianeb@feevale.br

Submissão: 21 de setembro de 2020

Aceitação: 07 de dezembro de 2020

\section{Resumo}

Uma dificuldade vivenciada pelos centros urbanos é o gerenciamento adequado dos resíduos sólidos gerados. Os resíduos cujos impactos têm maior alcance requerem atenção especial. Existem resíduos de serviços de saúde (RSS) gerados no ambiente domiciliar por pessoas acometidas de alguns tipos de enfermidades. Um destes casos são os portadores de diabetes melito. Para controlar a doença, os pacientes usam insulina injetável em seus domicílios; e os resíduos produzidos pela insulinoterapia são um grande problema de saúde pública. O objetivo deste estudo foi analisar como os usuários de insulina manejam os RSS em seus domicílios no que se refere a sua segregação, seu acondicionamento e sua disposição final. Trata-se de uma pesquisa exploratória descritiva, com abordagem quantitativa. Uma amostra de 42 pacientes selecionados a partir de critérios predeterminados respondeu a um questionário elaborado com base em um estudo acadêmico anterior. A análise dos resultados mostra que $28,5 \%$ separam os resíduos em domicílio, enquanto $36 \%$ os descartam em lixeira comum, e que a maioria não sabe para onde encaminhar os resíduos e apenas $26 \%$ receberam algum tipo de orientação sobre esse manejo. Este estudo conclui que há necessidade de implantação de programas educativos eficientes que possam oferecer orientações corretas aos pacientes insulinodependentes e que tenham o olhar voltado para questões ambientais.

Palavras-chave: Descarte; Insulinoterapia; Resíduos dos Serviços de Saúde; Resíduos Sólidos

\section{Abstract}

One difficulty experienced by the urban centers is the generation of solid waste and its adequate management. Impact wastes with greater reach require special attention. There are waste from health services (HSW) generated in domestic manner by people that have a disease called Diabetes Mellitus. For the control, injectable insulin is used in their homes, and the production of these residues in their residences is a major public health problem. The aim of the study was to analyze how the handling of HSW is carried out, at the household level of insulin users, with regard for segregation, packaging and final disposal. The research was carried out through data collection with a directed questionnaire. 42 patients responded. It was observed that $28.5 \%$ separate the residues at home, while $36 \%$ discard the residues in a common trash, most do not know where to send the residues and only $26 \%$ received some type of guidance on this management. The need to implement efficient educational programs to address this context was identified.

Keywords: Disposal; Insulin Therapy; Health Service Waste; Solid Waste 


\section{INTRODUÇÃO}

Vários desafios cercam a complexidade dos centros urbanos, entre eles está o descarte dos resíduos sólidos, que provoca excessivo impacto socioambiental. O mau gerenciamento dos resíduos sólidos nas cidades tem grande impacto no meio ambiente e na saúde da população. Se as cidades não gerenciarem corretamente os resíduos que produzem, estes serão um dos maiores fatores de poluição dos solos e do ar, causando até mesmo inundações pela falta de coleta e disposição inadequada (REIS; CONTI; CORREA, 2015).

O diabetes melito (DM), que é definido pela Organização Mundial de Saúde como um transtorno metabólico de causas diversas e de etiologia complexa, acomete muitas pessoas no Brasil e no mundo. O Ministério da Saúde o caracteriza por hiperglicemia e distúrbios no metabolismo de carboidratos, proteínas e gorduras, resultantes de defeitos da secreção e/ou da ação da insulina produzida pelo pâncreas. Um aliado no tratamento do diabetes melito é o monitoramento do nível glicêmico por meio do teste capilar rápido realizado com a utilização de lancetas, dispositivos perfurocortantes para puncionar a extremidade do dedo e coletar uma amostra de sangue, a partir da qual se pode mensurar a glicemia. Esse teste proporciona uma forma fácil de se promover um maior controle metabólico da doença. Para o controle da doença, muitos também utilizam insulina injetável em seus domicílios, fazendo o uso de seringas, agulhas, canetas com insulina e frascos de medicamentos (BRASIL, 2013b).

No estado do Rio Grande do Sul, no ano de 2014, por meio da Política Estadual de Resíduos Sólidos do Rio Grande do Sul (PERS-RS), instituída com a lei no 14528 (RIO GRANDE DO SUL, 2014), foram definidos os princípios, os objetivos os instrumentos e as diretrizes para o gerenciamento dos resíduos sólidos. Com esse documento, definiram-se também as responsabilidades inerentes aos geradores dos resíduos sólidos e as do poder público quanto à sua classificação, sua origem e periculosidade.

Os resíduos produzidos em domicílios a partir de insulinoterapia pertencem aos grupos: A (seringas, fitas reagentes com sangue e algodões com sangue), $B$ (restos de insulina nos frascos) e $E$ (agulhas, lancetas, canetas e frascos de insulina), que devem ser gerenciados por pessoas capacitadas para a atividade e encaminhados aos estabelecimentos de saúde de referência para serem descartados adequadamente (BRASIL, 2005).

Diante desse contexto, os profissionais da saúde têm um grande papel na orientação dos pacientes que fazem uso de insulinoterapia. A orientação fornecida é fundamental para capacitar os portadores de diabetes a realizarem o seu tratamento e o manejo dos resíduos produzidos.

O objetivo deste estudo foi analisar como é realizado o manejo dos RSS produzidos pelo tratamento domiciliar dos pacientes usuários de insulina assistidos por um plano de saúde do Vale do Rio do Sinos, no que se refere à sua segregação, ao seu acondicionamento e à sua disposição final.

\section{MATERIAIS E MÉTODOS}

O estudo caracterizou-se como uma pesquisa exploratória descritiva, com abordagem quantitativa. Foi realizado em um município da região do Vale do Rio dos Sinos, no sul do Brasil. No município estudado, durante os meses de maio e junho de 2019, foram realizadas entrevistas, através de contato telefônico, com portadores de diabetes usuários de insulina atendidos por uma operadora de um plano de saúde. Dentre estes, encontraram-se 740 pessoas, mas apenas 103 dos entrevistados faziam uso de insulinoterapia, os demais participantes do estudo faziam o controle da doença por meio de antiglicemiantes orais. A seleção dos participantes obedeceu aos seguintes critérios: assinarem o termo de consentimento, serem portadores de diabetes, independentemente do tipo, fazerem uso de insulinoterapia em seus domicílios e serem assistidos pela operadora de plano de saúde que participou do estudo. Foram excluídas da pesquisa aquelas pessoas que faziam uso de insulina por menos de 3 meses para que fossem mantidos apenas aquelas que já tivessem algum histórico de consumo e de descarte dos RSS produzidos em seus domicílios. Enquadraram-se nos critérios estabelecidos neste estudo 42 pessoas.

A pesquisa foi realizada através de um questionário dirigido, com 30 perguntas que continham variáveis sociodemográficas, dados sobre a insulinoterapia e informações sobre o descarte dos RSS produzidos. Esse questionário foi adaptado com base no referencial teórico do estudo feito por Andre (2010). Os dados de percentual e a associação de informações coletadas foram realizados na Universidade 
Feevale, através do teste qualitativo QuiQuadrado, utilizando-se o software Statistical Package for the Social Sciences v.26.0 (SPSS). Este estudo obedeceu à resolução número 466/2012 do Conselho Nacional de Saúde publicada em 2013 (BRASIL, 2013a). O projeto foi aprovado pelo Comitê de Ética da Universidade Feevale, sob o número 3010442.

\section{RESULTADOS E DISCUSSÃO}

Foram analisados os dados e as respostas de quarenta e dois usuários que praticam a insulinoterapia em seus domicílios, sendo possível verificar como é realizado o manejo dos RSS produzidos por essa prática no que se refere à sua segregação, seu acondicionamento e sua disposição final.

A tabela 1 apresenta dados referentes ao perfil socioeconômico e cultural dos participantes do estudo.

A maioria dos pacientes tinha mais de 50 anos (95\%), o que pode ser explicado pelo fato de a amostra ser composta por pacientes de DM tipo 2 $(81 \%)$, que acomete indivíduos de idade avançada, como mencionado por American Diabetes Association (ADA, 2010). Outro dado importante achado na amostra foi o grau de escolaridade, a maioria possui ensino fundamental incompleto $(26 \%)$ e apenas $17 \%$ possuem ensino superior completo. A maior parte dos participantes é composta por aposentados (88\%). Tal condição também pode interferir nos hábitos de vida e na realização do autocuidado, conforme apontam dados do Ministério da Saúde (BRASIL, 2012). Quanto ao sexo dos participantes, $50 \%$ da amostra era do sexo feminino e $50 \%$, do masculino, diferente do que se encontra na literatura dessa área. Tem sido constatado que a maioria dos usuários de insulina é do sexo feminino, pois as mulheres apresentam maior tendência para desenvolver diabetes do que os homens (BRASIL, 2012). O percentual igual entre os dois sexos pode ser explicado pelo número amostral. Possivelmente em uma amostra maior esse percentual poderia se assemelhar àqueles encontrados em outros estudos.

$\mathrm{Na}$ tabela 2, podem-se verificar dados sobre a prática de insulinoterapia dos usuários.

Tabela 1 - Perfil socioeconômico e cultural dos usuários de inulina

\begin{tabular}{ll}
\hline Variáveis & $\mathrm{n}=42$ \\
\hline Sexo & \\
Masculino & $21(50 \%)$ \\
Feminino & $21(50 \%)$ \\
Escolaridade & $11(26,1 \%)$ \\
Ensino fundamental incompleto & $8(19 \%)$ \\
Ensino fundamental completo & $5(11,9 \%)$ \\
Ensino médio incompleto & $8(19 \%)$ \\
Ensino médio completo & $3(7 \%)$ \\
Ensino superior incompleto & $7(17 \%)$ \\
Ensino superior completo & $2(5 \%)$ \\
Idade (em anos) & $40(95 \%)$ \\
40-49 & \\
$>50$ & $26(62 \%)$ \\
Renda Familiar & $3(7 \%)$ \\
Não informado & $6(14 \%)$ \\
Até 1 salário-mínimo & $7(17 \%)$ \\
De 1 a 2 salários-mínimos & \\
De 3 a 4 salários-mínimos & $3(7 \%)$ \\
Situação Ocupacional & $37(88 \%)$ \\
Empregado & $2(5 \%)$ \\
Aposentado & \\
Do Lar &
\end{tabular}

Fonte: autoras. 
Tabela 2 - Dados sobre a prática de insulinoterapia

\begin{tabular}{ll}
\hline Variáveis & $\mathrm{n}=42$ \\
\hline Há quanto tempo faz uso de insulina & \\
De 3 meses a 1 ano & $3(7 \%)$ \\
De 1 a 5 anos & $7(17 \%)$ \\
$>5$ anos & $32(76 \%)$ \\
Qual tipo de diabetes & \\
Diabetes tipo 1 & $3(7 \%)$ \\
Diabetes tipo 2 & $34(81 \%)$ \\
Não sabe informar & $5(12 \%)$ \\
Como adquire a insulina, seringas, agulhas e ou canetas para aplicação da \\
medicação & \\
Farmácia e ou drogaria & 36 \\
Unidade Básica de Saúde & $(85,5 \%)$ \\
Outros & $5(12 \%)$ \\
Tipo de insulina que faz uso & $1(2,5 \%)$ \\
NPH & \\
Regular & $9(21 \%)$ \\
NPH e Regular & $3(7 \%)$ \\
Não sabe informar & $11(26 \%)$ \\
Faz autoaplicação de insulina & $19(46 \%)$ \\
Não & $6(14 \%)$ \\
Às vezes & $32(76 \%)$ \\
\hline Fon & $4(10 \%)$ \\
\hline
\end{tabular}

Fonte: autoras.

A prática de insulinoterapia, na maioria da amostra (76\%), é realizada há mais de cinco anos, o que confere aderência ao hábito de aplicação da medicação. O uso da insulina NPH e da regular correspondeu a $26 \%$ dos entrevistados, enquanto $46 \%$ não sabiam informar o tipo de insulina usado. Vale observar que o tipo de insulina aplicada implica uma prática de aplicação e um manejo de controle glicêmico diferentes, com maior ou menor volume de insumos utilizados (AMERICAN DIABETES ASSOCIATION, 2010).

Sabe-se que, no Brasil, desde 2006 os pacientes portadores de DM têm o direito de receber o tratamento, seja o medicamento oral ou a insulina e seus insumos, para manter o controle glicêmico adequado (ANDRÉ; TAKAYANAGUI, 2015). Na amostra estudada, $85,5 \%$ adquirem a insulina e os insumos em drogarias e farmácias; e poucos, em unidades de saúde. Junto com o recebimento do tratamento, é necessário que seja fornecida a orientação adequada do descarte dos RSS, o que cabe ao mesmo profissional que orientou o tratamento. Os responsáveis por fazerem essas orientações normalmente são os enfermeiros, mas nem todos esses profissionais possuem a informação adequada para a finalidade, conforme mostra o estudo de André e Takayanagui (2015).

A tabela 3 apresenta o volume dos resíduos produzidos com a prática de insulinoterapia em domicílios.

Pode-se observar que a maioria dos sujeitos da pesquisa faz uso de algum tipo de seringa e agulha para aplicar a insulina, $36 \%$ usam seringa descartável acoplada com agulha, 12\% usam seringa descartável com agulha separada e 10\% utilizam ambas as seringas. Mas verifica-se que existem aqueles que não utilizam seringas e agulhas, utilizam apenas canetas $(42 \%)$, as quais possuem o medicamento e a agulha num mesmo produto, mais fácil de ser utilizado por um leigo. Pode-se observar que a maioria, $71 \%$, utiliza entre 1 e 10 seringas ou canetas por mês para o tratamento e uma pequena parcela, $15 \%$, utiliza mais de 30 seringas e ou canetas mensalmente. $\mathrm{Na}$ amostra, 100\% usam algum tipo de agulha, seringa ou caneta para a aplicação do tratamento. 
Esse dado corrobora os encontrados em pesquisas realizadas sobre essa temática e traz a preocupação com o manejo dos RSS produzidos em domicílios. A legislação brasileira ainda é incompleta e pouco específica com relação ao descarte final, apesar de, com o passar dos anos, ter havido um aumento da preocupação com relação à gestão dos RSS em nível mundial.

Ramos (2017), em sua pesquisa, encontrou dados semelhantes aos da amostra deste estudo, ou seja, a maioria dos sujeitos descartando os RSS produzidos em domicílio junto aos resíduos comuns ou em recipientes não resistentes, que chegam danificados à sua destinação final. Esta informação nos direciona para a elaboração de projetos que promovam a orientação adequada dos insumos do tratamento, preferencialmente durante as informações iniciais sobre os medicamentos a serem utilizados. Cabe ao profissional da saúde orientar sobre o descarte dos resíduos, inclusive de maneira ilustrativa. Mas deve fornecer informações consolidadas para favorecer a conscientização e a formação de uma sociedade participativa.

Tabela 3 - Volume dos Resíduos de Serviço de Saúde (RSS) produzidos em domicílios

Variáveis

Seringa descartável acoplada com agulha

Seringa descartável com agulha separada

Ambas as seringas

Não utiliza seringas, pois usa canetas

$\mathrm{n}=42$

\section{Quantidade de seringas ou canetas utilizadas/mês}

De 1 a 10

De 11 a 20

$15(36 \%)$

$5(12 \%)$

$4(10 \%)$

$18(42 \%)$

De 21 a 30

$30(71 \%)$

$3(7 \%)$

$3(7 \%)$

Mais de 30

$6(15 \%)$

Quantas vezes usa insulina por dia

$1 \mathrm{vez}$

2 vezes

$16(38 \%)$

$17(41 \%)$

4 vezes

$9(21 \%)$

Costuma fazer o teste de glicemia em domicílio

$42(100 \%)$

Com qual frequência costuma fazer o teste de glicemia

$1 \mathrm{vez} / \mathrm{dia}$

2 vezes/dia

$9(21 \%)$

$5(12 \%)$

3 vezes/dia ou mais

$12(29 \%)$

1 a 2 vezes/semana

$5(11,5 \%)$

Mais de 3 vezes na semana

$1(2,5 \%)$

Não realiza frequentemente

$10(24 \%)$

Usa a mesma seringa mais de uma vez

Não usa

2 vezes

$19(45 \%)$

3 vezes

$6(15 \%)$

Mais de 3 vezes

$3(7 \%)$

$14(33 \%)$

Usa a mesma agulha mais de $1 \mathrm{vez}$

Não usa

$19(45 \%)$

2 vezes

$7(17 \%)$

3 a 4 vezes

$4(10 \%)$

Mais de 4 vezes

$12(28 \%)$

Fonte: autoras. 
No que se refere ao reaproveitamento de seringas, $15 \%$ informaram que as utilizam por duas vezes, $7 \%$ por três vezes e $33 \%$ por mais de três vezes. Em relação às agulhas, $17 \%$ disseram que as reaproveitam duas vezes, $10 \%$ de três a quatro vezes e $28 \%$ mais de quatro vezes.

Constata-se também que $100 \%$ dos participantes fazem 0 teste de glicemia em domicílio. Sendo que $29 \%$ realizam o teste três vezes ao dia ou mais. Cerca de $21 \%$ realizam o teste de glicemia uma vez ao dia, $12 \%$ duas vezes ao dia e $11,5 \%$ realizam a testagem de uma a duas vezes por semana. Pode-se verificar que $24 \%$ têm regularidade na realização do teste de glicemia. Foi observado também que $38 \%$ fazem uso de insulina apenas uma vez ao dia, $41 \%$ duas vezes ao dia e $21 \%$ três vezes ao dia.

Tabela 4 - Informações sobre instrução da educação em saúde

\begin{tabular}{lc}
\hline Variáveis & $\mathrm{n}=42$ \\
\hline Você recebeu orientações sobre o descarte dos RSS & \\
Sim & $11(26 \%)$ \\
Não & $31(74 \%)$ \\
Já aconteceu algum acidente com este material & \\
Sim & $1(2,5 \%)$ \\
Não & $41(97,5 \%)$ \\
Você separa os resíduos produzidos na insulinoterapia & \\
Sim & $29(69 \%)$ \\
Não & $13(31 \%)$ \\
\hline
\end{tabular}

Fonte: autoras.

$\mathrm{Na}$ tabela 4 , verifica-se que apenas $26 \%$ dos usuários de insulina receberam algum tipo de instrução sobre como descartar os materiais utilizados, sendo que $74 \%$ que utilizam insulina não receberam nenhuma orientação. Observa-se também que apenas $69 \%$ afirmam que separam os resíduos oriundos da prática de insulinoterapia do lixo comum, sendo que $31 \%$ afirmam que nem sequer os separam. Observa-se que para realizar a segregação adequada, os usuários nem sempre necessitam receber orientação detalhada, pois é de domínio público o conhecimento de que agulhas, seringas e materiais perfurocortantes são potencialmente perigosos se descartados junto ao resíduo comum.

Pode-se evidenciar a necessidade de uma educação adicional sobre o descarte dos resíduos utilizados na prática de insulinoterapia domiciliar, visto que, mesmo que apenas $31 \%$ não realizem o descarte correto, esse volume já é capaz de gerar um dano ao meio ambiente se desprezado em local incorreto. $O$ tratamento do diabetes melito requer muitos conhecimentos por parte dos usuários, já que é necessário compreender a doença, a sua fisiopatologia, conhecer a indicação dos medicamentos utilizados e como descartá-los.
A transmissão dessas informações implica um acompanhamento constante por parte dos profissionais de saúde para que os pacientes aprendam não só a lidar com a doença, mas também a fazer o descarte dos RSS corretamente, agindo de acordo com as normas vigentes.

Quando questionados sobre a ocorrência de algum acidente durante o manuseio do material usado no tratamento, 97,5\% afirmaram não ter conhecimento de acidentes, apenas 2,5\% relataram acidentes com os perfurocortantes.

Os descartes de seringas, agulhas, canetas e frascos de insulinas, assim como de lancetas, são diferenciados. Para cada tipo de material, há uma forma diferente, como mostrou a pesquisa realizada por André em Ribeirão Preto em 2010. $\mathrm{Na}$ amostra do material coletado nessa pesquisa, foram encontradas $53,9 \%$ de lancetas em garrafas plásticas e $23,1 \%$ misturadas ao resíduo comum (ANDRE, 2010). O correto seria armazenar os materiais perfurocortantes em recipientes rígidos $\mathrm{e}$ resistentes. Acredita-se que armazená-los de forma imprópria torna passível a ocorrência de acidentes.

$\mathrm{Na}$ tabulação cruzada entre as perguntas: "você recebeu orientações sobre o descarte dos 
RSS?" e "você separa os resíduos produzidos na insulinoterapia?", nota-se que $50 \%$ dos sujeitos da pesquisa não receberam orientação sobre 0 descarte do resíduo, porém fazem a sua separação. Não há associação estatisticamente significativa entre as variáveis de orientação sobre o descarte e a separação do resíduo $\left(\chi^{2}=0,094, p\right.$ $=1,000)$ ou $\left(\chi^{2}=0,094, p>0,05\right)$. Pode não haver uma relação direta entre receber orientações pelo profissional de saúde e descarar corretamente os RSS, pois o conhecimento sobre o correto manejo dos resíduos pode não ter como fonte apenas os profissionais que acompanham esses pacientes, já que existem outras formas de instrução disponíveis na sociedade.

$\mathrm{Na}$ tabela 5, estão descritas as informações referentes às condições de segregação, acondicionamento e disposição final dos resíduos de serviço de saúde utilizados pelos usuários de insulina em domicílio.

Responderam que a coleta pública de resíduos acontece mais do que três vezes na semana $41 \%$ dos participantes. Cerca de $33 \%$ responderam que a coleta de resíduos passa três vezes na semana em suas ruas, enquanto $21 \%$ afirmaram que a coleta pública de resíduos é realizada duas vezes na semana. Apenas 5\% afirmaram que a coleta de resíduos é realizada uma vez na semana.

Perguntados sobre a frequência do descarte do material separado, $28,5 \%$ responderam que descartam o material uma vez por mês, $19 \%$ uma vez a cada dois meses, $17 \%$ uma vez por semana e 2,5\% fazem esse descarte três vezes por ano. E $33 \%$ afirmaram que não separam os resíduos.

Tabela 5 - Condições de segregação, acondicionamento e disposição final dos Resíduos do Serviço de Saúde

\begin{tabular}{ll}
\hline Variáveis & $\mathrm{n}=42$ \\
\hline Qual a frequência de coleta pública de lixo/ semana na sua rua & \\
1 vez/ semana & $2(5 \%)$ \\
2 vezes/ semana & $9(21 \%)$ \\
3 vezes/ semana & $14(33 \%)$ \\
Mais de 3 vezes/ semana & $17(41 \%)$ \\
Com qual frequência você descarta o material separado & \\
Não realiza separação & $14(33 \%)$ \\
1 vez/ semana & $7(17 \%)$ \\
1 vez/ mês & $12(28,5 \%)$ \\
1 vez/ 2 meses & $8(19 \%)$ \\
3 vezes/ ano & $1(2,5 \%)$ \\
Como coloca seringas, agulhas e lancetas para descartá-las & \\
Não utiliza & $6(14 \%)$ \\
Garrafa de polietereftalato de etileno (PET) & $6(14 \%)$ \\
Recipiente rígido resistente & $6(14 \%)$ \\
Recipiente próprio para material perfurocortante. & $6(14 \%)$ \\
Lixo comum & $15(36 \%)$ \\
Outros & $2(5 \%)$ \\
Qual destino é dado a este material (seringas, agulhas e lancetas) & \\
Não utiliza & \\
Entrega na unidade de saúde pública & $6(14 \%)$ \\
Entrega no serviço de saúde privado & $10(24 \%)$ \\
No lixo comum, mas separado & $6(14 \%)$ \\
Lixo comum e não separados & $15(36 \%)$ \\
Guarda em casa & $4(9,5 \%)$ \\
Como coloca fitas reagentes para descartá-las & $1(2,5 \%)$ \\
Não utiliza & \\
Garrafa de polietereftalato de etileno (PET) & \\
Recipiente rígido resistente & $3(7 \%)$ \\
Lixo comum & $6(14 \%)$ \\
\hline & $9(21 \%)$ \\
& $7(17 \%)$ \\
naro para material perfurocortante & $14(34 \%)$ \\
\hline
\end{tabular}


Outros

Qual destino é dado a este material (fitas reagentes)

Não utiliza

Entrega na unidade de saúde pública

$3(7 \%)$

Entrega no serviço de saúde privado

$7(17 \%)$

$11(26 \%)$

No lixo comum, mas separado

$13(30,5 \%)$

Lixo comum e não separados

$7(17 \%)$

Guarda em casa

Como coloca frascos de insulina para descartá-los

Não utiliza

Garrafa de polietereftalato de etileno (PET)

$18(43 \%)$

$4(9,5 \%)$

$7(17 \%)$

$3(7 \%)$

Recipiente próprio para material perfurocortante

Lixo comum

$9(21 \%)$

Outros

$1(2,5 \%)$

Qual destino é dado a este material (frascos de insulina)

Não utiliza

Entrega na unidade de saúde pública

$18(43 \%)$

Entrega no serviço de saúde privado

$9(21 \%)$

$1(2,5 \%)$

No lixo comum, mas separado

$9(21 \%)$

Lixo comum e não separados

$4(10 \%)$

Guarda em casa

$1(2,5 \%)$

Como coloca canetas de insulina para descartá-las

Não utiliza

Garrafa de polietereftalato de etileno (PET)

$21(50 \%)$

Recipiente rígido resistente

Recipiente próprio para material perfurocortante

Lixo comum

Outros

Qual destino é dado a este material (canetas de insulina)

Não utiliza

Entrega na unidade de saúde pública

Entrega no serviço de saúde privado

Lixo comum e não separados

$4(9,5 \%)$

Fonte: autoras.

Formularam-se questões específicas sobre como são realizados o acondicionamento e a disposição final de cada tipo de material com potencial de risco de contaminação ambiental diferente. Quanto às seringas, agulhas e lancetas utilizadas nos testes de glicemia, $14 \%$ afirmaram não as utilizar, $36 \%$ relataram que as acondicionam junto aos resíduos comuns, $14 \%$ em garrafas $\mathrm{PET}, 14 \%$ em recipiente rígido resistente, $14 \%$ em recipiente específico para material perfurocortante e $5 \%$ relataram que acondicionam o material de outros modos. Ainda sobre estes materiais, quando perguntados sobre a sua disposição final, $36 \%$ afirmaram que os dispõem junto ao resíduo comum, mas separadamente, $24 \%$ entregam os RSS em uma unidade de saúde pública, $14 \%$ os encaminham ao serviço de saúde privado, enquanto $9,5 \%$ os descantam junto ao resíduo comum, sem separá-los. A surpresa na pesquisa se deu quando $2,5 \%$ dos participantes relataram armazenar esses materiais em uma caixa, deixando-os em casa, e nunca os descartar.

$\mathrm{Na}$ tabulação cruzada entre as perguntas: "com qual frequência você descarta o material separado?" e "como coloca seringas, agulhas e lancetas para descartá-las?", nota-se que 23,8\% dos sujeitos da pesquisa não realizam a separação do resíduo, que é colocado no lixo comum. Há uma associação estatisticamente significativa entre as variáveis separação do resíduo e descarte $\left(\chi^{2}=\right.$ $32,448, p=0,039)$ ou $\left(\chi^{2}=32,448 p<0,05\right)$. Isso evidencia o descuido com o descarte dos materiais 
que têm potencial risco de contaminação ambiental.

$\mathrm{Na}$ pesquisa de Viana e colaboradores (2017), foram encontrados resultados similares, apenas metade da população em análise descartava os materiais em recipientes rígidos. Embora todos os participantes tenham sido orientados quanto ao descarte apropriado do material, 57,1\% descartavam os resíduos gerados pela administração de insulina de forma inapropriada no lixo comum.

Nesse contexto, pode-se reafirmar a necessidade da elaboração de uma cartilha com instruções básicas e adequadas para o manejo desses resíduos e com informações sobre acesso a consultas, caso isso ainda se faça necessário.

$\mathrm{Na}$ tabulação cruzada entre as perguntas: "com qual frequência você descarta o material separado?" e "qual destino é dado ao material de seringas, agulhas e lancetas?", evidencia-se que $14,3 \%$ dos sujeitos da pesquisa realizam o descarte uma vez por mês e entregam os RSS em uma unidade de saúde pública, enquanto 16,7\% dos sujeitos separam o resíduo, porém descartam o material no lixo comum. Há uma associação estatisticamente significativa entre as variáveis frequências de descarte e destino dado ao material $\left(\chi^{2}=35,762, p=0,016\right)$ ou $\left(\chi^{2}=35,762 p<0,05\right)$. Vale frisar que não basta fornecer informações sobre o armazenamento dos RSS, é preciso também informar o lugar apropriado para o encaminhamento desse material, visto que cabe ao usuário a responsabilidade da sua entrega em um local onde o tratamento correto será providenciado.

Em estudos realizados por Ichtiaq e colaboradores (2012) e por Kalra e colaboradores (2017), também foram demonstrados elevados percentuais de descarte inapropriado de resíduos decorrentes da insulinoterapia; e a possível razão para tal achado foi atribuída ao resultado insatisfatório da educação continuada sobre esse tema entre os usuários de insulina em domicílios. Como consequência, há aumento do risco de contaminação do meio ambiente, de transmissão de patógenos e de acidentes com perfurocortantes, o que demanda intensificação de medidas sanitárias e maior comprometimento dos profissionais de saúde na orientação da comunidade.

Um estudo realizado na França, Bélgica, Luxemburgo, Suíça e Tunísia revelou que 52,2\% dos sujeitos descartavam as lancetas junto aos resíduos comuns, enquanto $28,9 \%$ afirmaram descartá-las em garrafas plásticas, o que gera impactos ambientais importantes (BOUHANICK; HADJADJ; WEEKERS, 2000).

O acondicionamento dos resíduos é parte muito importante no seu descarte e precisa ser mais bem orientado, pois, para que o RSS chegue ao seu destino sem que o recipiente seja danificado, este precisa ser seguro, resistente aos materiais perfurocortantes e a possíveis vazamentos de líquidos como, por exemplo, caixas de papelão com paredes duplas e revestidas internamente por plásticos. Para André (2010), a contaminação por meio de vetores é a maior responsável por causar acidentes aos trabalhadores que manejam esses resíduos, pois roedores e insetos podem transmitir muitas doenças se estes resíduos estiverem dispostos de forma inadequada.

Quando perguntados sobre as fitas reagentes para realizar os testes de glicemia, nas quais resíduos de sangue ficam impregnados, 7\% afirmaram não utilizar esse material, 34\% relataram que as acondicionam junto ao resíduo comum, sem fazer a separação, $21 \%$ em recipientes rígidos resistentes, $17 \%$ em recipientes específicos para material perfurocortante, $14 \%$ em garrafas PET e 7\% em outros tipos de recipiente. Sobre a disposição final desses materiais, 30,5\% afirmaram que os descartam junto ao resíduo comum, mas fazem a sua separação, 26\% entregam esses RSS ao serviço de saúde privado, $17 \%$ os encaminham a uma unidade de saúde pública, enquanto $17 \%$ os descartam junto ao resíduo comum, sem separá-los, e 2,5\% dos participantes armazenam esses materiais em casa.

$\mathrm{Na}$ tabulação cruzada entre as perguntas: "como coloca fitas reagentes para descartá-las" e "qual destino é dado ao material de fitas reagentes?", identifica-se que $9,5 \%$ dos sujeitos de pesquisa colocam esse material em garrafas PET, enquanto $9,5 \%$ dos sujeitos as colocam em recipientes rígidos, que encaminham para uma unidade de saúde pública. Há uma associação estatisticamente significativa entre as variáveis armazenamento e destino dado ao material $\left(\chi^{2}=\right.$ $71,345, p=0,000)$ ou $\left(\chi^{2}=71,345, p<0,05\right)$. Podese constatar que os indivíduos que armazenam corretamente também encaminham corretamente os resíduos produzidos.

Os indivíduos com diabetes constituem o maior grupo de usuários de seringas e agulhas no mundo. Segundo as estimativas, são utilizadas mais de 7,5 bilhões de seringas. No entanto, esse 
número não corresponde à quantidade de lancetas usadas por diabéticos, que são 25 milhões de pessoas (BIÇER, 2018).

Em relação aos frascos com resíduos de insulina após a sua aplicação, $43 \%$ afirmaram que não utilizam o medicamento, $21 \%$ relataram que os acondicionam junto ao resíduo comum, $17 \%$ em recipientes rígidos resistentes, $9,5 \%$ em garrafas $\mathrm{PET}, 7 \%$ em recipientes específicos para material perfurocortante e $2,5 \%$ relataram que os acondicionam de outras formas.

Sobre o local da disposição final dos frascos de insulina, $43 \%$ não utilizam esse medicamento. Quanto aos que fazem uso do medicamento, 21\% informaram que entregam o material em uma unidade de saúde pública, $21 \%$ afirmaram que os descartam junto aos resíduos comuns, mas colocam o material separadamente, enquanto $10 \%$ colocam os frascos junto ao resíduo comum sem fazer qualquer separação. Dos demais participantes, $2,5 \%$ encaminham o RSS ao serviço de saúde privado e $2,5 \%$ relataram armazenar esses materiais em casa.

$\mathrm{Na}$ tabulação cruzada entre as perguntas: "como coloca frascos de insulina para descartálos" e "qual destino é dado ao material de frascos de insulina?", observa-se que $11,9 \%$ dos sujeitos de pesquisa que utilizam insulina, descartam os frascos no lixo comum. Há uma associação estatisticamente significativa entre as variáveis armazenamento e destino dos frascos de insulina $\left(\chi^{2}=93,593, p=0,000\right)$ ou $\left(\chi^{2}=93,593, p<0,05\right)$. Constatou-se novamente que os indivíduos que realizam o armazenamento adequado dos frascos de insulina para descarte também dão um destino adequado a esse material.

A pesquisa também perguntou sobre 0 descarte das canetas para aplicação de insulina, que ficam com resíduos de medicamento e a agulha acoplada, 50\% afirmaram não utilizar esse instrumento, $24 \%$ relataram que as acondicionam junto ao resíduo comum sem fazer a separação, $9,5 \%$ em recipientes específicos para material perfurocortante, $7 \%$ em recipientes rígidos resistentes, $5 \%$ em garrafas PET e $5 \%$ de outras formas. Sobre a disposição final dessas canetas, $14 \%$ afirmaram que as colocam junto ao resíduo comum, mas separadamente dos demais resíduos, $14 \%$ as entregam ao serviço de saúde privado, $12 \%$ as encaminham para uma unidade de saúde pública, enquanto $9,5 \%$ as descartam no lixo comum, sem fazer a separação.

$\mathrm{Na}$ tabulação cruzada entre as perguntas: "como coloca canetas de insulina para descartá- las" e "qual destino é dado às canetas de insulina?", identifica-se que $11,9 \%$ dos sujeitos da pesquisa que utilizam canetas de insulina, as descartam no lixo comum. Há uma associação estatisticamente significativa entre as variáveis de armazenamento e destino das canetas de insulina $\left(\chi^{2}=80,523, p=0,000\right)$ ou $\left(\chi^{2}=80,523, p<0,05\right)$. Nesse caso, observa-se que os indivíduos utilizam canetas para o tratamento não as descartam de maneira correta.

$\mathrm{Na}$ tabulação cruzada entre as perguntas: "qual sua escolaridade?" e "você separa os resíduos produzidos na insulinoterapia?", percebese que entre os sujeitos com os níveis de escolaridade fundamental incompleto, médio completo e superior completo, $14,3 \%$ descartam o resíduo separadamente.

Não há associação estatisticamente significativa entre escolaridade e descarte, $\left(\chi^{2}=\right.$ $2,574, p=0,765)$ ou $\left(\chi^{2}=2,574, p>0,05\right)$. $\mathrm{Na}$ amostra estudada, não houve relações entre o grau de instrução do sujeito e o correto manejo dos resíduos produzidos em seus tratamentos.

Estudos em todo o mundo têm demonstrado que diabéticos descartam resíduos médicos inapropriadamente. Um estudo realizado no Nepal verificou que as formas mais comumente utilizadas para eliminar de agulhas usadas foram: transferilas para os veículos municipais de descarte de resíduos, jogá-las em lugares isolados e queimálas (BIÇER, 2018).

Na tabulação cruzada entre as perguntas: "há quanto tempo faz uso de insulina?" e "você separa os resíduos produzidos na insulinoterapia?", notase que $57,1 \%$ dos sujeitos da pesquisa com mais de cinco anos de uso de insulina separam os resíduos. Nesta pesquisa, não se constatou uma associação estatisticamente significativa entre o tempo de uso de insulina com a separação de resíduos, $\left(\chi^{2}=4,165, p=0,125\right)$ ou $\left(\chi^{2}=4,165, p\right.$ $>0,05)$. Na amostra estudada, o tempo de uso de insulina no tratamento e o correto manejo dos resíduos não podem ser levados em consideração.

Este estudo está de acordo com estudos anteriores que identificaram que pacientes diabéticos que já tinham sido aconselhados e instruídos sobre como usar e descartar adequadamente os resíduos da insulinoterapia tinham maior probabilidade de fazê-lo adequadamente do que aqueles que nunca tinham sido orientados.

Outro estudo na Índia descobriu que pacientes diabéticos que receberam de seus 
médicos a informação sobre como eliminar os resíduos da insulinoterapia eram menos propensos a descartá-los diretamente no lixo doméstico, em comparação com aqueles que nunca haviam sido informados (HASAN et al., 2019).

\section{CONCLUSÕES}

As unidades de saúde que prestam assistência aos usuários de insulina em nível domiciliar devem explicar qual a melhor forma de manejo dos RSS. Devem também orientar esses pacientes sobre a melhor maneira de transportar esses resíduos e sobre como acondicioná-los e indicar o melhor local para o seu descarte. Os usuários de insulina podem e devem entregar os RSS produzidos no ambiente domiciliar em locais que fornecem o acompanhamento do DM, tais como: as clínicas de saúde que façam coleta e sejam pontos de destinação de RSS, as unidades de saúde da atenção básica do SUS e os hospitais que atendem esses pacientes. Além disso, essas unidades devem fornecer orientação aos usuários de insulina sobre quais são os locais que já fazem o encaminhamento adequado dos RSS e, por essa razão, devem recebê-los para que o seu descarte seja efetivado corretamente.

A construção de uma cartilha contendo as informações relevantes para o manejo adequado dos resíduos de insulina é uma sugestão para amenizar a problemática evidenciada neste trabalho. A partir do conjunto dos dados obtidos na pesquisa, pode-se concluir também que os resultados revelam a necessidade de se implantarem normas e rotinas norteadoras para os profissionais da saúde, assim como programas educativos eficientes que tratem essas questões com o olhar voltado para o meio ambiente e para o correto tratamento dos pacientes insulinodependentes.

\section{REFERÊNCIAS}

AMERICAN DIABETES ASSOCIATION. Diagnosis and classification of Diabetes Mellitus. Diabetes Care, Alexandria (USA), v. 33, n. 1, p. 62-69, 2010. Disponível em: <https://doi.org/10.2337/dc09-S062>. Acesso em: jan. 2020.

ANDRE, S. C. S. Resíduos gerados em domicílios de indivíduos com diabetes mellitus, usuários de insulina. 2010. Dissertação de Mestrado em Ciências) - Escola de Enfermagem de Ribeirão Preto,

Universidade de São Paulo, Ribeirão Preto, SP, 2010.
ANDRÉ, S. C. S.; TAKAYANAGUI, A. M. M.

Orientações sobre o descarte de resíduos gerados em domicílios de usuários de insulina. Revista Baiana de Saúde Púbica, Salvador, BA, v. 39, n. 1, p. 105-118, 2015. doi: 10.5327/Z0100-0233-2015390100010

BIÇER, E. K. An important environmental risk from patients with diabetes using insulin: Disposal of medical waste. Current Research in Diabetes and Obesity Journal, Antakya (Turquia), v. 7, n. 5, 2018. doi: 10.19080/CRDOJ.2018.07.555725.

BOUHANICK, B.; HADJADJ, S.; WEEKERS, L. What do the needles, syringes, lancets and reagents strips of diabetic patients become in the absence of a common attitude? Diabetes e Metabolismo, Paris (França), v. 26 , n. 4, p. 288-93, 2000.

BRASIL. Conselho Nacional do Meio Ambiente. Resolução Conama no 358, de 29 de abril de 2005. Dispõe sobre o tratamento e a disposição final dos resíduos dos serviços de saúde e dá outras providências. Diário Oficial da União, Poder Executivo, Brasília, DF, 04 maio 2005. Seção 1, p. 6365. Disponível em: $<$ http://www.hemocentro.fmrp.usp.br/wpcontent/uploads/legislacao/Resolucao\%20Conama\%20 358\%20de\%2029\%2004\%202005.pdf>. Acesso em: out. 2019.

BRASIL. Ministério da Saúde. Secretaria de Atenção à Saúde. Departamento de Atenção Básica. Caderno de Atenção Domiciliar. v. 1. Brasília, 2012. Disponível em:

<http://189.28.128.100/dab/docs/publicacoes/geral/cad _vol1.pdf>. Acesso em: maio 2020.

BRASIL, Ministério da Saúde. Conselho Nacional de saúde. Resolução no 466, de 12 de dezembro de 2012. Aprova Diretrizes e Normas Regulamentadoras de Pesquisa Envolvendo Seres Humanos. Diário Oficial da União, Poder Executivo, Brasília, DF, 13 jun. 2013a. Disponível em:

<http://conselho.saude.gov.br/resolucoes/2012/Reso46 6.pdf>. Acesso em: maio 2020.

BRASIL. Ministério da Saúde. Secretaria de Atenção à Saúde. Departamento de Atenção Básica. Cadernos de Atenção Básica, № 36. Brasília, DF, 2013b. Disponível em:

$<$ https://bvsms.saude.gov.br/bvs/publicacoes/estrategia s_cuidado_pessoa_diabetes_mellitus_cab36.pdf > . Acesso em: maio 2020.

HASAN, U. A. et al. Factors contributing to sharp waste disposal at health care facility among diabetic patients in North-East Peninsular Malaysia. International Journal of Environmental Research and Public Health, Basel (Suíça), v. 16, n. 13, p. 2251, 2019. doi: 10.3390/ijerph16132251 
ISHTIAQ, O. et al. Disposal of syringes, needles, and lancets used by diabetic patients in Pakistan. Journal of Infection and Public Health, King Abdulaziz Medical City, (Arábia Saudita), v. 5, n. 2, p. 182-188, 2012. doi: 10.1016/j.jiph.2012.02.002

KALRA, S. et al. Indian injection technique study: population characteristics and injection practices. Diabetes Therapy, Llandough, (Reino Unido), v. 8, n. 3, p. 637- 57, 2017. doi: 10.1007/s13300-017-0243-x

RAMOS, H. M. P. Descarte de medicamentos e perfurocortantes no Distrito Federal: um olhar sobre a sociedade e os catadores de materiais recicláveis. 2017. Dissertação (Mestrado em Ciências e Tecnologias em Saúde) - Universidade de Brasília, Brasília, DF, 2017.
REIS, M. F.; CONTI, D.; CORREA, R. M. Gestão de resíduos sólidos: desafios e oportunidades para a cidade de São Paulo. RISUS - Journal on Innovation and Sustainability, São Paulo, SP, v. 6, n. 3, p. 77-96, 2015. doi: 10.24212/2179-3565.2015v6i3p77-96

RIO GRANDE DO SUL. Assembleia Legislativa. Lei no 14.528, de 16 de abril de 2014. Institui a Política Estadual de Resíduos Sólidos e dá outras providências. Diário Oficial do Estado, Poder Legislativo, Porto Alegre, 17 abr. 2014.

VIANNA, M. S. et al. Self-care competence in the administration of insulin in older people aged 70 or over. Revista Latino-Americana de Enfermagem, Ribeirão Preto, SP, v. 25, e2943. 2017. doi: $10.1590 / 1518-8345.2080 .2943$ 